1 The genome of the Balearic shearwater (Puffinus mauretanicus),

7 Gonzalez-Solís ${ }^{5}$, Marta Riutort ${ }^{1^{*}}$, Julio Rozas $^{1^{*}}$

1. Department of Genetics, Microbiology \& Statistics, Faculty of Biology \& Institute for 13

5. Department of Evolutionary Biology, Ecology and Environmental Sciences, Faculty of

\title{
evolutionary and conservation genomics
}

\author{
a Critically Endangered seabird: a valuable resource for
}

Cristian Cuevas-Caballé ${ }^{1}$, Joan Ferrer Obiol ${ }^{1,2}$, Joel Vizueta $^{1,3}$, Meritxell Genovart ${ }^{4}$, Jacob Research on Biodiversity (IRBio), Universitat de Barcelona (UB)

2. Department of Environmental Science and Policy, Università degli Studi di Milano (UniMi)

3. Villum Centre for Biodiversity Genomics, Section for Ecology and Evolution, Department of Biology, University of Copenhagen, Copenhagen, Denmark

4. Mediterranean Institute for Advanced Studies (IMEDEA) CSIC-UIB \& Centre for Advanced Studies of Blanes (CEAB), CSIC

Biology \& Institute for Research on Biodiversity (IRBio), Universitat de Barcelona (UB) 
${ }^{*}$ corresponding authors

27 Abstract

The Balearic shearwater (Puffinus mauretanicus) is the most threatened seabird in Europe. The fossil record suggests that human colonisation of the Balearic Islands resulted in a sharp decrease of the population size. Currently, populations continue to be decimated mainly due to predation by introduced mammals and bycatch in longline fisheries, and some studies predict their extinction by 2070 . We present the first highquality reference genome for the species which was obtained by a combination of short and long-read sequencing. Our hybrid assembly includes 4,169 scaffolds, with a scaffold $\mathrm{N} 50$ of $2.1 \mathrm{Mbp}$, a genome length of $1.2 \mathrm{Gbp}$, and BUSCO completeness of $96 \%$, which is amongst the highest across sequenced avian species. This reference genome allowed us to study critical aspects relevant to the conservation status of the species, such as an evaluation of overall heterozygosity levels and the reconstruction of its historical demography. Our phylogenetic analysis using whole-genome information resolves current uncertainties in the order Procellariiformes systematics. Comparative genomics analyses uncover a set of candidate genes that may have played an important role into the adaptation to a pelagic lifestyle of Procellariiformes, including those for the enhancement of fishing capabilities, night vision and the development of natriuresis. This reference genome will be the keystone for future developments of genetic tools in conservation efforts for this Critically Endangered species.

\section{Keywords}

50 Balearic shearwater, conservation genomics, comparative genomics, Procellariiformes 51 marine adaptation 


\section{Background}

The genomic sequence of a species accumulates valuable information on the evolutionary history, including demographic and selective events, and on the evolution of genes and traits [1-4], information that it is also crucial for the emerging field of conservation genomics [5]. The genetic diversity within a species represents a reservoir of adaptive variation that can help populations to cope with environmental variability [6]. Understanding the processes that shape genetic diversity and its distribution pattern within species is paramount to assess the conservation status or the factors responsible for a species decline [7] [8]. This knowledge can inform the proposal of effective conservation and management plans, as for instance the definition of management units [9]. In this context, next-generation sequencing (NGS) techniques allow the analysis of an increased density of markers across the genome, providing unprecedented accuracy in the estimations of population genetic parameters relevant for scientific-based conservation recommendations [10].

Among the Critically Endangered species listed by the IUCN Red List (IUCN 2021), we find the Balearic shearwater (Puffinus mauretanicus Lowe, 1921) (Figure 1a) belonging to the most diverse order of seabirds, the Procellariiformes. This order has a worldwide distribution and comprises more than 140 species (IUCN 2021) in four families: petrels and shearwaters (Procellariidae); northern storm petrels (Hydrobatidae); southern storm petrels (Oceanitidae) and albatrosses (Diomedeidae). All species show many morphological, physiological and life history traits associated with their adaptation to a pelagic lifestyle. They are long-lived with deferred sexual maturity, low fecundity (all lay a single egg), colonial breeders, socially (and mostly sexually) monogamous, highly phylopatric and with prominent salt gland at the base of the bill, adaptations for underwater 
vision to fish as well as a particularly acute sense of smell, among other traits [12]. Within this apparent homogeneity, the group shows a large variation in body mass and lifestyles, ranging from $20 \mathrm{~g}$ to $15 \mathrm{~kg}$, from bodies shaped for diving (e.g. short strong wings used for wing-propelled diving) to those prepared for an extremely vagile lifestyle (thin elongated wings) and from a continuous flapping to dynamic soaring flight modes. Currently, their phylogenetic relationships present some conflicting issues [13,14], such as the position of albatrosses, whether storm petrels (Families Hydrobatidae and Oceanitidae) constitute a monophyletic group, and whether diving-petrels (genus Pelecanoides) should be considered an independent family from Procellariidae.

The Balearic shearwater is a medium-sized pelagic seabird endemic to the Balearic Islands. Its population size is undergoing a fast annual decline of $7.4-14 \%[15,16]$ mostly due to bycatch in longline fisheries and predation by invasive mammals in the colonies [17-19]. Currently, it has a reduced number of breeding pairs (estimated as ca. 3,200, Arcos, 2011, with a total population size up to 30,000 individuals due to the vast contingent of floaters [21,22]. Genetic studies based on mtDNA and microsatellites found that this species has low levels of genetic diversity and high inbreeding coefficients [23]. Although local inbreeding and natal philopatry can contribute to a reduction in population size, the actual worst menace for the species comes from human activities, and a population viability study based on demographic modeling predicted that the species would become extinct by 2070 [15].

Indeed, a population viability study based on demographic modeling predicted that the species would become extinct by 2070 [15]. Moreover, studies based on mitochondrial markers [24] and also on morphology and migratory behaviour [25], suggested a possible 
103

104

105

106

107

108

109

110

111

ongoing hybridization and introgression process between Balearic and Mediterranean ( $P$. yelkouan) shearwaters, which may represent an additional threat for the species.

Here, we (1) provide a high-quality reference genome for the Balearic shearwater along its structural and functional annotations; (2) estimate genome-wide heterozygosity and the historical demography of the species by performing Multiple Sequentially Markovian Coalescent (MSMC) analyses; (3) revisit the phylogeny of the order by using this genome together with seven additional Procellariiformes genomes released by the B10K [3], and (4) uncover genes putatively involved in Procellariiformes adaptation to pelagic life. The high-quality genome of the most endangered seabird in Europe presented here will be the base for further population-based conservation genomics studies.

\section{Data description}

\section{Sampling, DNA and RNA extraction and sequencing}

We sampled two Balearic shearwater adults and one chick. Adults were sampled on Sa Cella colony, Mallorca (male) and on Sa Conillera, Eivissa (unsexed) in 2004, while the chick was sampled on Conills islet (Mallorca) in July 2019. From here on the animals will be referred to as male-MII, unsexed-Ei and chick-MII, respectively. Special permits to obtain the samples were issued by Conselleria de Medi Ambient, Agricultura i Pesca (Govern de les Illes Balears, Spain).

We extracted DNA from blood samples preserved in absolute ethanol for both adults. The DNA extraction for the male-MII was performed with DNeasy Blood \& Tissue Kit (Qiagen) following the manufacturer's instructions, and with Blood \& Cell Culture DNA Mini Kit (Qiagen) for the unsexed-Ei. RNA was extracted from the chick-Mll's blood cells preserved 
130 in RNAlater 1:5 using the RNeasy Mini Kit (Qiagen) according to the manufacturer's

131 protocols. We performed the quality control with gel electrophoresis and NanoDrop One

132 (Thermo Fisher Scientific, Waltham, MA, USA), and the quantification with an Invitrogen

133 Qubit Fluorometer 2.0 (Broad Range kit).

134

135 We obtained the reference genome combining short-read and long-read sequencing

136 libraries, and using RNA-seq data to assist with the annotation. First, an Illumina TruSeq

137 DNA PCR Free library (insert size $=350$ bp) was prepared by Macrogen (South Korea)

138 using DNA from male-MIl, and sequenced using two HiSeq X Ten runs (2x150bp).

139 Second, long-read libraries were prepared, from the DNA of unsexed-Ei, using the Ligation

140 kit SQK-LSK109 1D from ONT (Oxford Nanopore Technologies) (N50 of 9431 bp) at

141 CNAG (Centro Nacional de Análisis Genómico, Spain) and sequenced through five runs of

142 MinION on FLO-MIN106 flow cells. Third, we prepared RNA sequencing (RNA-seq)

143 libraries from the chick-Mll's RNA using the TruSeq RNA Sample Prep Kit v2 with Ribo-

144 Zero, and we sequenced the libraries on a NovaSeq 6000 (2x100bp) (Macrogen, South

145 Korea).

146

\section{Analyses}

149 Sequencing data and Genome assembly and annotation

150

151 Illumina paired-end (2x150 bp) sequencing of the male-MII yielded a throughput of 147.7

152 Gbp (Table 1), representing a mean coverage of 118x. The five runs of ONT sequencing

153 of the unsexed-Ei resulted in a 10x coverage with a read N50 of 9,431 bp. RNA

154 sequencing of the chick-MII (2x100 bp) yielded 15 Gbp of data. 
155 We obtained a hybrid assembly with MaSuRCA formed by 4,169 scaffolds, with an N50 of

$1562.1 \mathrm{Mbp}$, and an assembly length of $1.21 \mathrm{Gbp}$ (Table 2, Figure 1b). The completeness

157 analysis using BUSCO yields a value of $95.9 \%$, and only $0.3 \%$ of the complete genes were

158 duplicated and $1.1 \%$ were fragmented (Table 2). Our de novo repeat annotation analysis

159 shows that $9.95 \%$ of the genome consists of repetitive regions (Table S1), which is within

160 the range of previously sequenced avian genomes [26]. Among repeat elements, long

161 interspersed nuclear elements (LINEs) were the most abundant $(4.45 \%$ of the genome).

162 The genome annotation process resulted in a total of 21,959 protein-coding genes, of

163 which 18,769 (85.5\%) have at least one GO associated term, and 19,218 (87.5\%) have

164 hits across the surveyed curated databases (Table S2).

165

166 Blood transcriptome assembly from the chick-MIl resulted in 224,904 transcripts (Table

167 S3). However, BUSCO completeness was only $62.4 \%$, which was far below genome

168 completeness, probably due to the RNA coming from a single not very transcriptionally

169 active tissue.

170

171 The assembly of the mitogenome of $P$. mauretanicus resulted in a single contig of 19,885

172 bp long, with a coverage (Illumina reads) of $371 x$, which is around three times higher than

173 the coverage of the nuclear genome. This mitogenome has the same gene order as other

174 published Procellariiformes' mitogenomes (Figure S1). The mitogenome has two copies of

175 the nad6 gene, as predicted in $P$. Iherminieri [27]; the later feature was also confirmed

176 analysing the mean coverage (illumina reads) across genes (Table S4).

Historical demography of the Balearic shearwater

180 Balearich shearwater PSMC' analysis showed support for a steady growth in population 181 size from an originally low population size followed by a sudden increase 200 kya (Figure 
182 1c). High population size did not last long and suffered a sudden decrease to nearly one

183 tenth of the population coinciding with the end of the glacial period before the last

184 interglacial period (119-128 kya) and a prolonged period of low sea level (Figure 1c).

185 Hereafter, $N_{e}$ remained stable until $\sim 10$ kya ago, as more recent MSMC2 time segments

186 are regarded as being unreliable [28].

188 Genome-wide heterozygosity in $P$. mauretanicus was 0.0024 , which is within the range of 189 genome-wide heterozygosities estimated for other Procellariiformes (ranging from 0.0014

190 in T. chlororhynchos to 0.0037 in P. urinatrix) (Figure 2a). Among Procellariiformes, small-

191 bodied species tended to have higher mean heterozygosities but also higher variance than

192 large-bodied species (Figure 2b).

193

194 Phylogenetic relationships

195

196 OrthoFinder analysis estimated 6,172 single copy (1:1) ortholog genes across the 12

197 genomes surveyed. With this data we generated three supermatrices: 1) CDS supermatrix

198 of $10,534,506$ bp long to extract the 4D sites, 2) 4D supermatrix with $1,512,677$-fold

199 degenerate sites, and 3) the amino acid supermatrix including 3,466,564 sites.

200 Phylogenetic analyses using the 4D and the amino acid supermatrices recovered the 201 same topology with full support at all nodes (ultrafast bootstrap = 100; Figures S2 and S3).

203 The analysis performed to explicitly account for incomplete lineage sorting (ILS) with 204 ASTRAL using either the individual gene sequences (CDS gene trees) or the individual 205 amino acid sequences (amino acid gene trees), produced species trees with the same 206 topology as those obtained by ML using 4D or amino acid supermatrices (Figures S4 and 207 Figure S5). The normalized quartet score (proportion of input gene tree quartet trees in 
agreement with the species tree) was 0.78 for CDS gene trees and 0.64 for amino acid

209 gene trees.

211 The ultrametric tree (Figure 3) obtained using r8s from the 4D supermatrix ML tree 212 summarizes the recovered topology. In this topology, the Atlantic yellow-nosed albatross 213 (T. chlororhynchos, Diomedeidae) is the sister group to all the other Procellariiformes. We 214 also find that storm petrels (Hydrobatidae and Oceanitidae) do not constitute a 215 monophyletic group. In addition, diving petrels (Pelecanoides) are included within 216 Procellariidae.

$\underline{\text { Comparative Genomics and Positive selection analyses }}$

220 To identify genes associated with adaptation to a pelagic lifestyle in the Procellariiformes, 221 we performed a positive selection analysis across 12 species including eight 222 Procellariiformes species applying the HyPhy aBSREL model. We identified the hallmark 223 of positive selection in 20 (out of the 6,172 single-copy orthologs genes), after correcting 224 for multiple testing (Table S5). The enriched GO analysis uncovered terms related with 225 striated muscle cell differentiation, nutrient reservoir activity, response to starvation, visual 226 learning, positive regulation of neural retina development, olfactory receptor activity or 227 natriuresis (Table S6). We also performed an analysis to assess the global impact of 228 natural selection in Procellariformes (both positive and negative selection), which 229 uncovered a total of 310 genes (Table S7). The GO terms enriched in these genes include 230 wound healing, response to wounding, inflammatory response, sensory perception of 231 sound, smell and chemical stimulus, neurological system process, defense response, 232 response to stress, camera-type eye development, renal system and chloride transport 233 among others (Table S8). 
235 Using OrthoFinder 2.3.8, we identified 182,487 N:N orthogroups across all genes identified 236 in the 12 analysed genomes. This data, together with the estimated ultrametric tree, was 237 used to estimate gene gains, losses, and number of genes in the ancestral nodes using 238 BadiRate; for the analysis we selected the Free Rates (FR) model, since it was the best 239 fitted branch model. The analysis was conducted including all orthogroups, and the 240 minimum number of gains and losses per branch is represented in Figure 3. Our analysis 241 showed a tendency to gain genes in Procellariiformes (+442/-34), while the branch leading 242 to albatrosses (Diomedeidae) showed an opposite effect, with a noticeable loss of genes $243(+464 /-3258)$; the branch leading to the rest of the Procellariiformes $(+379 /-15)$ is in the 244 line of the general behavior of the tubenoses (Table S9). Within the order, families 245 Oceanitidae and Hydrobatidae present the same trend, with the branch leading to $H$. 246 thethys presenting a stronger gene loss balance $(+325 /-966)$ than the branch leading to 247 the ancestor of Oceanitidae (O. oceanicus and F. grallaria (+182/-414)).

249 We identified three gene families significantly expanded in the branch leading to the 250 Procellariiformes (Table S9). These families encode zinc finger proteins (OG0000000), 251 olfactory receptors (OG0000084) and avian histones (OG0000224).

\section{Discussion}

257 The assembly length and the GC content of the Balearic shearwater hybrid assembly 258 presented here are similar to those reported in the seven Procellariiformes genomes 259 released by the $\mathrm{B} 10 \mathrm{~K}$ [3]. Albeit repetitive content is remarkably higher $(+33.4 \%)$ in the 
260 Balearic shearwater in comparison to the other genomes of the order, but within the range 261 of avian genomes [26]. This difference of up to a third can be due to the fact that we 262 included a Procellariiform (C. borealis) repeat library prior to running RepeatMasker, 263 achieving a more precise library that encloses clade related repeats that are present in the 264 genome but not found by the de novo RepeatModeler library. The genome assembly 265 completeness (BUSCO 95.9\%) is slightly higher than the obtained for other recently 266 published bird genomes [3,29], and even higher than genome assemblies including optical 267 mapping [30]. Despite not being a chromosome-scale assembly, contiguity is also quite 268 high (N50 2.1 Mbp), and higher than recent avian MaSuRCA hybrid assemblies [31,32].

269 The retrieved proteome (21,959 protein-coding genes) is similar to previous genomes $270[33,34]$, but higher than the B10K 2020 genomes used in the comparative studies in this 271 work (mean of $16 \mathrm{~K}$ ). This is probably due to the B10K annotation pipeline being fully 272 based on homology, whilst we also used de novo prediction. The functional annotation 273 quality in terms of genes having at least a GO term (85.9\%) is comparable to recent 274 chromosome-scale genomes [34].

276 The mitogenome of $P$. mauretanicus spans $19,885 \mathrm{bp}$, exhibiting the same order and the 277 nad6 gene duplication observed in P. Iherminieri [27]. We did not find any cob duplication 278 as it occurs in the Diomedeidae family [35]. Our result supports that nad6 duplication could 279 be widespread in Procellariiformes [27], and, like cob, could have undergone various 280 events of deletion or addition during the diversification of the order. Nevertheless, since 281 some of the reported duplications could be artificial [36,37], to fully identify the true number 282 of gene duplications/deletions will require additional and specific experimental analyses. 
286 Current level of intraspecific heterozygosity is a relevant parameter to determine the 287 adaptive capacity of a population (or species) [38]. Since the Balearic shearwater is 288 categorised as Critically Endangered by the IUCN, we could naively expect low 289 heterozygosity levels in the species when compared to other Procellariiformes. However, 290 the fossil record suggests that the Balearic shearwater had a very large population 291 (>30.000 pairs) until the arrival of human settlers in the Balearic Islands [39], which hunted 292 shearwaters [40] and introduced invasive mammals that also predated on them [41]. In line 293 with Genovart, Oro, Juste, \& Bertorelle, (2007) results using mtDNA markers, we observed 294 relatively high genome-wide heterozygosity levels, suggesting that the very recent 295 demographic decline in the species is not yet visible in its genetic diversity.

297 Regarding the historical demography, our PSMC' analysis shows an increase in $N_{e}$ in the 298 Balearic shearwater from around 1 Mya to later expand to reach high population sizes, 299 until around 150,000 ya, when it suddenly suffered a sharp decline, resulting in lower $N_{\mathrm{e}}$ 300 values maintained until 10,000 years ago. Since current PSMC' analysis is based on the 301 analysis of a single genome, we could not reliably infer more recent events [28]. The Plio302 Pleistocene eustatic variations resulted in a loss of neritic zones as sea level regressed 303 [43], this may represent a loss of coastal habitat availability, which added to other 304 oceanographic alterations (changes in ocean circulation or productivity) may have been 305 the drivers of great population losses in marine megafauna, including seabirds. In the case 306 of the Balearic shearwater, the PSMC' analysis shows an abrupt decay of $N_{e}$ associated 307 with a long period of low sea level during the Penultimate Glacial Period ( 194-135 kya) 308 which may have resulted in an important loss of neritic zones.

310 Here, we have observed a negative correlation between heterozygosity and body size 311 within the Procellariiformes, where small-bodied species (O. oceanicus, F. grallaria, $H$. 
312 tethys and $P$. urinatrix) have higher heterozygosities than large-bodied species $(F$.

313 glacialis, C. borealis, P. mauretanicus and T. chlororhynchos). Although controversial,

314 contrasting heterozygosity levels between species with different body-sizes has also been

315 reported in different species including Procellariiformes [13]. Since body-size also

316 correlates with population size and with other life-history traits, current data does not allow

317 to determine the biological meaning of such correlation effect $[13,44]$.

319 In view of the critical population declines affecting the Balearic shearwater populations, 320 understanding its impacts on current genetic diversity of the species and among colonies 321 will be crucial to assess the conservation status of the Balearic shearwater. Future 322 ongoing research, using a more powerful population genomics approach, will allow to 323 reconstruct the most recent demographic history of the species and to test the fossil-based 324 hypotheses of a recent loss of population due to human colonization of the island, as well 325 as why heterozygosity values have not decayed.

327 Phylogeny of Procellariiformes

329 The study of the evolutionary relationships within the order Procellariiformes had until 330 recently been based mainly in the phylogenetic analyses of a single gene, the 331 mitochondrial cytochrome $b$ or on supertree approaches combining life history, 332 morphological and sequence data [45-47]. However, these approaches did not show 333 enough resolution for this group, leaving several open questions. The main points that 334 remain contentious are: 1) which family is the sister to the rest of the Procellariiformes 335 (Diomedeidae or Hydrobatidae), 2) which is the phylogenetic position of the diving petrels 336 (Pelecanoides sp.) and whether they should be placed on their own family, 3) the 337 monophyly of the storm petrels as well as the phylogenetic relationships among the 
338 speciose Procellariidae [48-51]. More recently, the first study to use genomic data to

339 resolve the backbone Procellariiformes phylogeny [13] reported a well-resolved phylogeny

340 of 51 species using 4,365 ultraconserved elements (UCEs). This phylogeny recovered the

341 albatrosses (Diomedeidae) as the sister group to the rest of Procellariiformes, the diving

342 petrels included within Procellariidae, and the storm petrels constituting a paraphyletic

343 group with Oceanitidae and Hydrobatidae being two separate monophyletic groups, and

344 Hydrobatidae as sister group of Procellariidae. Our phylogenomic results using a smaller

345 taxon sampling but a more extensive phylogenomic dataset (of up to 6,172 genes), agrees

346 with those of [13], supporting that these phylogenetic relationships are definitive.

348 Adaptation to a pelagic lifestyle in Procellariiformes

350 Our selection inference uncovered 20 genes evolving under positive selection in

351 Procellariiformes, being therefore candidates to be actively involved in the adaptation of

352 the order to a pelagic lifestyle. Indeed, the GO's Enrichment analysis of these genes

353 reveals biological processes related to striated muscle cell differentiation, response to

354 starvation, and nutrient reservoir activity, that may be related to the high energy

355 expenditure during the vast distances they cover in the open ocean, while visual related

356 genes could be related with underwater vision to fish and night vision [52-54]. Positive

357 selection of genes related to natriuresis also makes sense for Procellariiformes since this

358 biological process plays a key role to maintain the osmotic equilibrium in a sodium-rich

359 environment like the ocean [55,56], which Procellariiformes perform thanks to the

360 development of salt glands (modified nasal glands engaged in secretion of salts). Olfactory

361 receptors, also found here among enriched GOs of positively selected genes, showed

362 signature of adaptive evolution in shearwaters [57], and are crucial to Procellariiformes for 
363 navigation [58-60], partner recognition and mating [61-63], finding their own burrows [64]

364 or foraging [65-68].

365

366 We also inferred genes with intensified natural selection in Procellariiformes, for which the

367 GOs annotations (Table S8) are similar and coherent to those in the candidate set of

368 genes with positive selection in all tubenoses, or, in other words, related to the adaptation

369 of the order to a pelagic lifestyle. For example, molecular functions such as sensory

370 perception of sound, smell and chemical stimulus, neurological system process, camera-

371 type eye development are related with oceanic navigation. On the other hand, functions

372 such as homeostatic process, renal system, renal response, chloride transport and

373 regulation of ion transport point to the need of maintaining osmotic equilibrium. We also

374 found intensified natural selection in genes participating in functions related to immune

375 response (like inflammatory response, defense response, response to wounding, wound

376 healing, positive regulation of phagocytosis, etc.), accompanied by a relaxation of natural

377 selection in regulators of blood constituents, induction of bacterial agglutination, regulation

378 of antigen processing and presentation, viral budding via host ESCRT complex or

379 macrophage antigen processing and presentation. As Procellariiformes exposure to

380 parasites is high [69] and their life-history traits favour parasite maintenance within

381 populations [70], the tuning between the intensification and relaxation of natural selection

382 in multiple biological processes and molecular functions related with immune response

383 would have emerged following an arms race-like model. For example, as many parasites

384 of tubenoses are blood-feeding, the intensified natural selection on the thrombin-activated

385 receptor signaling pathway (GO:0070493), may be an evolutionary response to counter

386 the anticoagulant activity that most blood-feeding parasites present [71]. 
Among the gene families expanded in the branch of Procellariiformes, the one encoding olfactory receptors is remarkable as it is coherent not only with the finding of a gene with positive selection in all Procellariiformes with the same functional annotation (g16276.t1 in the $P$. mauretanicus reference annotation, Table 4) but also with 3 olfactory receptors genes with intensification selection in the same branch (g14377.t1, g16276.t1 and g17936.t1 in P. mauretanicus reference annotation, Table S8). This triple evidence highlights the importance of how the adaptation to a pelagic life resulted in the enhancement of the olfactory function in Procellariiformes, as we discussed already in the paragraphs above. Moreover, similar results of positive selection in olfactory genes were obtained in $C$. borealis [57]. Physiologically, tubenoses have one of the largest olfactory bulb to brain size $(\mathrm{OB})$ ratio of all birds [72]

\section{Conclusions}

Our study highlights the utility of the hybrid assembly strategy using Illumina and ONT at recovering high quality genome assemblies, especially regarding contiguity and completeness. Comparative genomics analyses identified candidate genes under selection to have played a major role in the adaptation of the Procellariiformes to a pelagic lifestyle such as changes in sensory perception, navigation, natriuresis and physiological adaptations. Regarding the phylogeny of Procellariiformes, our results gave full support to recent genomic based hypotheses in which albatrosses (Diomedeidae) are sister to the rest of Procellariiformes, storm petrels are paraphyletic and diving petrels are included within Procellariidae. The high-quality genome presented in this work will be a great tool for future population genomic analyses, that will reveal with more precision the genetic variability of the species, its recent demographic history and the potential introgression with its sister species, the Mediterranean shearwater ( $P$. yelkouan). The data obtained will 
414 be of great help in future proposals of conservation and management plans for the 415 species.

416

\section{Methods}

Genome Assembly

421 We performed a de novo hybrid genome assembly with MaSuRCA 3.3.1 [73], using short 422 (Illumina) and long (ONT) reads. Before the assembly step, we filtered the ONT reads with

a Phred quality score $(Q \geq 5)$ using the NanoFilt software included in NanoPack, [74].

424 Paired-end Illumina reads were parsed into MaSuRCA without any preprocessing, as 425 adapters and errors are handled by the QuORUM error corrector [75], which is part of the MaSuRCA pipeline. MaSuRCA was run applying the following parameters: fragment mean 427 (422), fragment stdev (312) and estimated genome size (1.2 Gbp). The resulting assembly was screened for contaminants with BlobTools v1.0 [76] -x bestsumorder. Assembly completeness was assessed with BUSCO 4.0.2 [77] using the 8,338 single-copy 430 conserved genes in aves_odb10 database [78].

Transcriptome Assembly

434 We trimmed RNA-seq raw reads for adapters with BBDuk 435 (https://sourceforge.net/projects/bbmap/) ( $\mathrm{k}=17$, tpe option), and used STAR 2.7.3a [79] 436 to map the filtered reads to the newly assembled reference genome. We obtained the 437 transcriptome assembly with Trinity 2.8.6 [80] using the genome-guided bam mode (-438 genome_guided_max_intron 82945). Transcripts were clustered with CD-HIT [81,82] 4.8.1 
439 (-c 0.98) and coding regions (CDS) were predicted with TransDecoder 5.5.0

440 (https://github.com/TransDecoder/).

\section{$442 \quad$ Mitogenome Assembly}

444 We trimmed adapters from Illumina raw reads with BBDuk ( $k=23$, tpe option), before 445 using them as input to NOVOPlasty 2.7 .2 [83]. The Puffinus Iherminieri mitogenome 446 (MH206163.1) was used as seed using the following parameters: Genome Range (16000447 24000), Insert size (422), Insert range (1.74) and Insert range strict (1.3). The annotation 448 was performed using the MITOS WebServer [84].

$\underline{\text { Repeat annotation }}$

We generated a de novo repeat library of the genome with RepeatModeler - 1.0.11 (Smit, Hubley, \& Green,) on scaffolds $>100 \mathrm{kbp}$. This library was combined with all avian and ancestral consensus repeats from Dfam_Consensus-20181026 [86], RepBase-20181026 [87] and the repeat annotation of the Cory's shearwater (Calonectris borealis) [3], which represents the most closely related sequenced genome. Redundancies among libraries were removed

with the script ReannTE_MergeFasta.pl (https://github.com/4ureliek/ReannTE). We then ran RepeatMasker 4.0 .7 [85] using the combined library as a reference, with the following parameters: -xsmall -e ncbi -s -gccalc no_is -gff.

\section{Structural and Functional Annotation}

464 We performed the structural annotation with BRAKER 2.1.2 (https://github.com/Gaius465 Augustus/BRAKER) (--etpmode) using data from both the Cory's shearwater proteome [3], 
466

467

468

469

470

471

472

473

474

475

476

477

478

479

480

481

482

483

484

485

486

487

488

489

490

491

and the RNA-Seq data generated in this work. Since the inclusion of RNA-Seq data appeared detrimental, we excluded this piece of information to perform the final annotation using the soft-masked genome with BRAKER 2.1.2 (--prg=gth --trainFromGth).

We made the functional annotation of the predicted genes using a similarity-based approach. We determined the protein domains with InterProScan 5.31-70.0 [88], used BLASTP [89,90] (-evalue 1e-5; -max_target_seqs 10) against the Swiss-Prot database [91] and the Cory's shearwater and the Zebra finch reference (UP000007754) proteomes. Transcripts were annotated in the same manner. We also annotated the ncRNAs using cmscan from INFERNAL 1.1.2 [92] with the covariance models (CMs) from the Rfam 14.1 database, and tRNA genes using tRNAscan-SE 2.0.5 [93].

\section{Demographic History}

We used MSMC2 [28] to infer the historical demography of the Balearic shearwater. MSMC2 implements a MSMC model, which allows the estimation of the effective population size $\left(N_{\mathrm{e}}\right)$ over time. To generate input files for MSMC2, we mapped Illumina short reads to scaffolds larger than $1 \mathrm{Mbp}$ (343 scaffolds spanning $71.8 \%$ of the assembled genome) using BWA-MEM 0.7.17 [94], as recommended in [95]. First, we called the SNPs using samtools mpileup (Samtools mpileup 1.9 -q $20-\mathrm{Q} 20$-C 50) and then bcftools $1.9-\mathrm{c}-\mathrm{V}$ indels. The input files were then generated by converting the SNPs obtained to MSMC input format using the bamCaller.py script accounting for the mean coverage of each scaffold. Multiple sequentially Markovian coalescent (MSMC) for two haplotypes, known as PSMC', was run with MSMC2 with time patterning specified as -p $1 * 4+30 * 2+1^{*} 4+1^{*} 6+1^{*} 10$. 
492 We ran 100 bootstraps of 29 pseudo-chromosomes [96] sampling 20 chunks of 1.508 .752

493 bp with replacement using multihetsep_bootstrap.py. We scaled time and population size

494 using a generation time for the Balearic shearwater of 12.8 years [15] and the Northern

495 fulmar (Fulmarus glacialis) mutation rate $\left(2.89 \times 10^{-9}\right.$ substitutions per nucleotide per 496 generation, [2].

498 Genome-wide heterozygosity

500 We estimated genome-wide heterozygosities using information of a single individual from 501 all eight Procellariiformes species studied. We applied the [97] method, with minor 502 modifications to take genome fragmentation into consideration, since we included genome 503 assemblies with varying amounts of contiguity. The DNA sequence data (genome 504 assemblies and whole-genome sequencing data) were downloaded from NCBI 505 (PRJNA261828, PRJNA545868; [1,3]. For each species, adapter-trimmed reads were 506 aligned to its genome assembly using bwa mem [98], bam files were merged using Picard507 Tools (http://broadinstitute.github.io/picard/) and variants were called using the GATK 4.1.9 508 HaplotypeCaller and GenotypeGVCFs [99]. Sites with a coverage $<1 / 3 X$ or $>2 X$ of the 509 average coverage depth (of the particular genome) were filtered out using VCFtools 0.1.15 510 [100]. We computed per-site heterozygosity as the proportion of heterozygous sites per 511 total number of called genotypes within a single individual in nonoverlapping $25 \mathrm{~Kb}$ 512 windows across each scaffold. Windows with less than $50 \%$ of net sites (those excluding 513 missing or filtered sites), were excluded from the analysis.

\section{Orthology inference}

517 We performed the phylogenomic and comparative genomics analyses including 518 information from 12 species with an available genome assembly: eight Procellariiformes 
519 (P. mauretanicus, Thalassarche chlororhynchos, Hydrobates tethys, Oceanites oceanicus,

520 Fregetta grallaria, Pelecanoides urinatrix, Fulmarus glacialis and Calonectris borealis), and

521 four outgroups, Aptenodytes forsteri, Pygoscelis adeliae (Sphenisciformes); Egretta

522 garzetta, Phalacrocorax carbo (Pelecaniformes). We inferred orthologous genes across

523 the proteomes of these 12 species using OrthoFinder 2.3.8 [101] with default parameters.

525 Phylogenetic relationships

527 We built a multiple sequence alignment (MSA) for each 1:1 orthologs with PRANK 528 v.100802 [102], using both coding sequences (CDS) (-codon -noxml -notree -F) and amino 529 acid sequences (-noxml -notree $-\mathrm{F}$ ). Individual alignments were concatenated with 530 catfasta2phyml v1.1.0 (https://github.com/nylander/catfasta2phyml) to create a CDS 531 supermatrix and an amino acid supermatrix. Only locus with data for all the twelve species 532 have been considered. Fourfold degenerate sites (4D) for the CDS supermatrix were 533 extracted with MEGA X [103]. We performed unpartitioned maximum likelihood (ML) 534 phylogenetic analyses using IQ-TREE 1.6.12 [104] (-bb 1000) both for 4D and amino acid 535 supermatrices. Optimal models of sequence evolution were obtained with ModelFinder 536 [105] according to Bayesian information criterion (BIC), and the resulting best-fit models 537 were $\mathrm{GTR}+\mathrm{F}+\mathrm{R} 2$ for $4 \mathrm{D}$ and $\mathrm{HIVb}+\mathrm{F}+\mathrm{R} 3$ for amino acid supermatrix. Node support was 538 obtained with Ultrafast Bootstrap [106].

540 To explicitly account for incomplete lineage sorting (ILS) under the Multispecies 541 Coalescent Model (MSC), we inferred the species tree using the summary coalescent 542 approach, as implemented in ASTRAL-III 5.6.3 [107]. We first obtained all gene trees (for 543 each 1:1 orthologous genes) using IQ-TREE 1.6.12, and inferred the species tree and its 544 normalized score (from both CDS and amino acid gene trees) using ASTRAL-III. 
546 We generated an ultrametric tree with r8s v.1.81 [108] using the 4D supermatrix ML tree.

547 We used four calibration points (in myr): root (max_age=84 min_age=73, [109]), most

548 recent common ancestor (MRCA) of Spheniscidae (min_age=12.6, [110]), MRCA

549 Procellariiformes (min_age=49, [111]), MRCA Procellariidae (min_age=14, [112]),

550 retrieved from TimeTree [113]. We used the penalized likelihood (PL) method and the

551 Truncated Newton (TN) algorithm, smoothing parameter was set to 100.

552

553 Positive Selection Analysis

554

555 We evaluated the selective constraints of genes that could be associated with pelagic

556 lifestyle. For this purpose, we performed the analysis with HyPhy 2.5 [114], using

557 Procellariiformes data (1:1 MSAs). Prior to the analysis, non-reliable positions across all

558 1:1 orthologs MSAs were filtered with ZORRO [115] (default options; MSA with average

559 quality $<5$ were filtered). We used the aBSREL method [116] to test for positive selection,

560 and the RELAX method [117] to test for relaxed/intensified selection. We also performed a

561 Gene ontology (GO) enrichment analysis of the candidate genes using the GOstats [118]

562 R package against the background GOs of 1:1 orthologs.

563

564 Gene family evolution

565

566 We estimated gene turnover rates, the number of gene gains and losses across the 567 phylogeny lineages, and inferred gene family contractions and expansions using BadiRate 5681.7 [119]. For the analysis we first inferred the orthogroups with OrthoFinder 2.3.8, and we 569 used the calibrated ultrametric tree estimated with r8s. We tested, under the Birth-Death570 Innovation (BDI) model for turnover rates, several biological relevant hypotheses with 571 three different branch models: Free Rates (FR), Global Rates (GR) and Branch-specific 
572 Rates (BR), and chose the best model based on the lowest AIC value. To ensure an

573 appropriate convergence we ran multiple times each model.

574

575

576 Acknowledgements

577

578 We are grateful to David García and Maite Louzao for kindly providing samples and the

579 Govern Illes Balears for research permits (CEP19/2019). This research was supported by

580 Fundación Banco Bilbao Vizcaya (Spain), Project 062-17; by the Ministerio de Economía y

581 Competitividad of Spain, projects CGL2016-78530-R, PGC2018-093924-B-100 and

582 PID2019-103947GB.

583

584

585

Author contributions

586

587 JFO, JGS, MR and JR, conceived the study. CCC, JFO, MG and JGS, performed 588 samplings. CCC, JFO performed wet lab work. CCC, JFO and JV performed the 589 bioinformatic analyses. CCC, JFO, MR and JR, interpreted the genomic data. MG, JGS 590 discussed on biological data. CCC, JFO, MR and JR drafted the first version of the 591 manuscript. All authors revised and approved the final version of the manuscript.

594 ORCID

595

596 Cristian Cuevas-Caballé https://orcid.org/0000-0003-4292-9777

597 Joan Ferrer Obiol https://orcid.org/0000-0002-1184-5434

598 Joel Vizueta https://orcid.org/0000-0003-0139-3013 
Meritxell Genovart https://orcid.org/0000-0003-2919-1288

600 Jacob González-Solís https://orcid.org/0000-0002-8691-9397

601 Marta Riutort https://orcid.org/0000-0002-2134-7674

602 Julio Rozas https://orcid.org/0000-0002-6839-9148

603

604

605

\section{Data Availability}

606

The whole-genome shotgun project has been deposited at DDBJ/ENA/GenBank under the

Bioproject PRJNA780920, and BioSamples SAMN24039388, SAMN23492024 and

611 structural and functional annotations, are available in https://github.com/molevol612 ub/Puffinus_mauretanicus_genome, and in the Supplementary Information online.

\section{References}

617 1. Jarvis ED, Mirarab S, Aberer AJ, Li B, Houde P, Li C, et al.. Whole-genome analyses

618 resolve early branches in the tree of life of modern birds. Science (80- ). 2014; doi: 10.1126/science.1253451.

620 2. Nadachowska-Brzyska K, Li C, Smeds L, Zhang G, Ellegren H. Temporal Dynamics of 621 Avian Populations during Pleistocene Revealed by Whole-Genome Sequences. Curr Biol. 622 2015; doi: 10.1016/J.CUB.2015.03.047.

623 3. Feng S, Stiller J, Deng Y, Armstrong J, Fang Q, Reeve AH, et al.. Dense sampling of 624 bird diversity increases power of comparative genomics. Nature. 2020; doi: 
626 4. Foote AD, Liu Y, Thomas GWC, Vinař T, Alföldi J, Deng J, et al.. Convergent evolution

627 of the genomes of marine mammals. Nat Genet 2015 473. 2015; doi: 10.1038/ng.3198.

628 5. Allendorf FW. Genetics and the conservation of natural populations: allozymes to

629 genomes. Mol Ecol. 2017; doi: 10.1111/mec.13948.

630 6. Dussex N, van der Valk T, Morales HE, Wheat CW, Díez-del-Molino D, von Seth J, et

631 al.. Population genomics of the critically endangered kākāpō. Cell Genomics. 2021; doi:

632 10.1016/J.XGEN.2021.100002.

633 7. Brüniche-Olsen A, Kellner KF, Belant JL, DeWoody JA. Life-history traits and habitat

634 availability shape genomic diversity in birds: implications for conservation. Proc $R$ Soc $B$.

635 2021; doi: 10.1098/RSPB.2021.1441.

636 8. Wang P, Burley JT, Liu Y, Chang J, Chen D, Lu Q, et al.. Genomic Consequences of

637 Long-Term Population Decline in Brown Eared Pheasant. Mol Biol Evol. 2021; doi:

638 10.1093/MOLBEV/MSAA213.

639 9. Funk WC, McKay JK, Hohenlohe PA, Allendorf FW. Harnessing genomics for

640 delineating conservation units. Trends Ecol. Evol.

641 10. Supple MA, Shapiro B. Conservation of biodiversity in the genomics era. Genome Biol.

642 2018; doi: 10.1186/s13059-018-1520-3.

643 11. . IUCN 2021. The IUCN Red List of Threatened Species. Version 2021-1.

644 https://www.iucnredlist.org.

645 12. Brooke M. Albatrosses and petrels across the world. :4992004;

646 13. Estandía A, Chesser RT, James HF, Levy MA, Obiol JF, Bretagnolle V, et al..

647 Substitution Rate Variation in a Robust Procellariiform Seabird Phylogeny is not Solely

648 Explained by Body Mass, Flight Efficiency, Population Size or Life History Traits. bioRxiv.

649 2021; doi: 10.1101/2021.07.27.453752.

650 14. Hackett SJ, Kimball RT, Reddy S, Bowie RCK, Braun EL, Braun MJ, et al.. A

651 phylogenomic study of birds reveals their evolutionary history. Science (80- ). 2008; doi: 
652

653

654

655

656

657

658

659

660

661

662

663

664

665

666

667

668

669

670

671

672

673

674

675

676

677

10.1126/science.1157704.

15. Genovart M, Arcos JM, Álvarez D, McMinn M, Meier R, B. Wynn R, et al.. Demography of the critically endangered Balearic shearwater: the impact of fisheries and time to extinction. Österblom H, editor. J Appl Ecol. 2016; doi: 10.1111/1365-2664.12622.

16. Oro D, Aguilar JS, Igual JM, Louzao M. Modelling demography and extinction risk in the endangered Balearic shearwater. Biol Conserv. 2004; doi: 10.1016/S00063207(03)00180-0.

17. Arcos, Louzao, Oro. Fisheries ecosystem impacts and management in the Mediterranean: seabirds point of view. Am Fish Soc Symp. :587-96 2008;

18. Louzao, Arcos, Hyrenbach, Sola D, Oro. Resultados preliminares sobre el hábitat de alimentación de la Pardela Balear en el Levante Ibérico Peninsular. Anu Ornitològic les Balear Rev d'observació Estud i Conserv dels aucells. :61-7 2004;

19. Martí, Ruiz. Ruiz, A., Martí, R. (Eds.) (2004). La pardela balear. SEO/BirdLife-

Conselleria de Medi Ambient del Govern de les Illes Balears. Madrid. 2004;

20. Arcos. Arcos, J.M. (compiler) 2011. International species action plan for the Balearic shearwater, Puffinus mauretanicus. SEO/BirdLife \& BirdLife International. 2011;

21. Arcos, Arroyo, Becares, Mateos-Rodriguez, Rodriguez, Muñoz, et al.. Arcos, J.M., Arroyo, G.M., Becares, J., Mateos-Rodríguez, M., Rodriguez, B., Muñoz, A.R. et al. (2012) New estimates at sea suggest a larger global population of the Balearic Shearwater Puffinus mauretanicus. Proc 13th Medmaravis Pan-Mediterranean Symp.

22. Arroyo GM, Mateos-Rodríguez M, Munõz AR, De La Cruz A, Cuenca D, Onrubia A. New population estimates of a critically endangered species, the Balearic Shearwater Puffinus mauretanicus, based on coastal migration counts. Bird Conserv Int. 2016; doi: 10.1017/S095927091400032X.

23. Genovart M, Juste J, Contreras-Díaz H, Oro D. Genetic and phenotypic differentiation between the critically endangered balearic shearwater and neighboring colonies of its 
678 sibling species. J Hered. 2012; doi: 10.1093/jhered/ess010.

679 24. Genovart M, Juste J, Oro D. Two sibling species sympatrically breeding: A new

680 conservation concern for the critically endangered Balearic shearwater. Conserv Genet.

681 2005; doi: 10.1007/s10592-005-9010-z.

682 25. Austin RE, Wynn RB, Votier SC, Trueman C, McMinn M, Rodríguez A, et al.. Patterns

683 of at-sea behaviour at a hybrid zone between two threatened seabirds. Sci Rep. 2019; doi:

684 10.1038/s41598-019-51188-8.

685 26. Zhang G, Li C, Li Q, Li B, Larkin DM, Lee C, et al.. Comparative genomics reveals

686 insights into avian genome evolution and adaptation. Science (80- ). 2014; doi:

687 10.1126/science.1251385.

688 27. Torres L, Welch AJ, Zanchetta C, Chesser RT, Manno M, Donnadieu C, et al..

689 Evidence for a duplicated mitochondrial region in Audubon's shearwater based on MinION

690 sequencing. https://doi.org/101080/2470139420181484116. 2018; doi:

$691 \quad 10.1080 / 24701394.2018 .1484116$.

692 28. Schiffels S, Wang K. MSMC and MSMC2: The Multiple Sequentially Markovian

693 Coalescent. Methods Mol Biol. 2020; doi: 10.1007/978-1-0716-0199-0_7.

694 29. Prost S, Armstrong EE, Nylander J, Thomas GWC, Suh A, Petersen B, et al..

695 Comparative analyses identify genomic features potentially involved in the evolution of

696 birds-of-paradise. Gigascience. 2019; doi: 10.1093/gigascience/giz003.

697 30. Peñalba J V., Deng Y, Fang Q, Joseph L, Moritz C, Cockburn A. Genome of an iconic

698 Australian bird: High-quality assembly and linkage map of the superb fairy-wren (Malurus

699 cyaneus). Mol Ecol Resour. 2020; doi: 10.1111/1755-0998.13124.

700 31. Leroy T, Anselmetti Y, Tilak M-K, Berard S, Csukonyi L, Gabrielli M, et al.. A bird's

701 white-eye view on avian sex chromosome evolution. bioRxiv. 2019; doi: 10.1101/505610.

702 32. Gan HM, Falk S, Morales HE, Austin CM, Sunnucks P, Pavlova A. Genomic evidence

703 of neo-sex chromosomes in the eastern yellow robin. Gigascience. 2019; doi: 
704

705

706

707

708

709

710

711

712

713

714

715

716

717

718

719

720

721

722

723

724

725

726

727

728

729

10.1093/gigascience/giz111.

33. Liu J, Wang Z, Li J, Xu L, Liu J, Feng S, et al.. A new emu genome illuminates the evolution of genome configuration and nuclear architecture of avian chromosomes.

Genome Res. 2021; doi: 10.1101/GR.271569.120.

34. Recuerda M, Vizueta J, Cuevas-Caballé C, Blanco G, Rozas J, Milá B. ChromosomeLevel Genome Assembly of the Common Chaffinch (Aves: Fringilla coelebs): A Valuable Resource for Evolutionary Biology. Genome Biol Evol. 2021; doi: 10.1093/GBE/EVAB034. 35. Abbott CL, Double MC, Trueman JWH, Robinson A, Cockburn A. An unusual source of apparent mitochondrial heteroplasmy: duplicate mitochondrial control regions in Thalassarche albatrosses. Mol Ecol. 2005; doi: 10.1111/J.1365-294X.2005.02672.X. 36. Formenti G, Rhie A, Balacco J, Haase B, Mountcastle J, Fedrigo O, et al.. Complete vertebrate mitogenomes reveal widespread repeats and gene duplications. Genome Biol. 2021; doi: 10.1186/S13059-021-02336-9/FIGURES/5.

37. Urantówka AD, Kroczak A, Mackiewicz P. New view on the organization and evolution of Palaeognathae mitogenomes poses the question on the ancestral gene rearrangement in Aves. BMC Genomics 2020 211. 2020; doi: 10.1186/S12864-020-07284-5.

38. Ørsted M, Hoffmann AA, Sverrisdóttir E, Nielsen KL, Kristensen TN. Genomic variation predicts adaptive evolutionary responses better than population bottleneck history. PLoS Genet. 2019; doi: 10.1371/JOURNAL.PGEN.1008205.

39. Alcover, J.A., Bover, P., Seguí B. No Title. Paleoecol les illes Ina JA (Ed), Ecol les Illes, Monogr la Soc Nat les Balear. p. 169-204.

40. Ramis D. Animal Exploitation in the Early Prehistory of the Balearic Islands. J Is/ Coast Archaeol. 2018; doi: 10.1080/15564894.2017.1334721.

41. Pinya S, Carretero MA. The Balearic herpetofauna: a species update and a review on the evidence. Acta Herpetol. 2011; doi: 10.13128/ACTA_HERPETOL-9579.

42. Genovart M, Oro D, Juste J, Bertorelle G. What genetics tell us about the conservation 
730 of the critically endangered Balearic Shearwater? Biol Conserv. 2007; doi:

731 10.1016/J.BIOCON.2007.02.016.

732 43. Pimiento C, Griffin JN, Clements CF, Silvestro D, Varela S, Uhen MD, et al.. The

733 Pliocene marine megafauna extinction and its impact on functional diversity. Nat Ecol Evol

7342017 18. 2017; doi: 10.1038/s41559-017-0223-6.

735 44. Mackintosh A, Laetsch DR, Hayward A, Charlesworth B, Waterfall M, Vila R, et al.. The 736 determinants of genetic diversity in butterflies. Nat Commun 2019 101. 2019; doi:

$737 \quad 10.1038 / \mathrm{s} 41467-019-11308-4$.

738 45. Nunn GB, Stanley SE. Body size effects and rates of cytochrome b evolution in tube-

739 nosed seabirds. Mol Biol Evol. 1998; doi:

740 10.1093/OXFORDJOURNALS.MOLBEV.A025864.

741 46. Kennedy M, Page RDM. Seabird Supertrees: Combining Partial Estimates of

742 Procellariiform Phylogeny. Auk. 2002; doi: 10.1093/AUK/119.1.88.

743 47. Penhallurick J, Wink M. Analysis of the taxonomy and nomenclature of the

744 Procellariiformes based on complete nucleotide sequences of the mitochondrial

745 cytochrome b gene. http://dx.doi.org/101071/MU01060. 2016; doi: 10.1071/MU01060.

746 48. Brown RM, Jordan WC, Faulkes CG, Jones CG, Bugoni L, Tatayah V, et al..

747 Phylogenetic Relationships in Pterodroma Petrels Are Obscured by Recent Secondary

748 Contact and Hybridization. PLoS One. 2011; doi: 10.1371/JOURNAL.PONE.0020350.

749 49. Welch AJ, Olson SL, Fleischer RC. Phylogenetic relationships of the extinct St Helena

750 petrel, Pterodroma rupinarum Olson, 1975 (Procellariiformes: Procellariidae), based on

751 ancient DNA. Zool J Linn Soc. 2014; doi: 10.1111/ZOJ.12078.

752 50. Obiol JF, James H, Chesser R, Bretagnolle V, Gonzales-Solis J, Rozas J, et al..

753 Paleoceanographic changes in the late Pliocene promoted rapid diversification in pelagic

754 seabirds. Authorea Prepr. 2020; doi: 10.22541/AU.160253833.37656353/V1.

755 51. Austin JJ, Bretagnolle V, Pasquet E. A Global Molecular Phylogeny of the Small 
756 Puffinus Shearwaters and Implications for Systematics of the Little-Audubon's Shearwater

757 Complex. Auk. 2004; doi: 10.1093/AUK/121.3.847.

758 52. Martin GR, De M. The eye of a procellariiform seabird, the Manx shearwater, Puffinus

759 puffinus: visual fields and optical structure. Brain Behav Evol. 1991; doi:

$760 \quad 10.1159 / 000114347$.

761 53. Hayes B, Martin GR, Brooke M de L. Novel Area Serving Binocular Vision in the

762 Retinae of Procellariiform Seabirds. Brain Behav Evol. 1991; doi: 10.1159/000114348.

763 54. Mitkus M, Nevitt GA, Danielsen J, Kelber A. Vision on the high seas: spatial resolution

764 and optical sensitivity in two procellariiform seabirds with different foraging strategies. $J$

765 Exp Biol. 2016; doi: 10.1242/JEB.140905.

766 55. Gutiérrez JS. Living in Environments with Contrasting Salinities: A Review of

767 Physiological and Behavioural Responses in Waterbirds.

768 https://doi.org/1013157/arla6122014233. 2014; doi: 10.13157/ARLA.61.2.2014.233.

769 56. . Water and Salt Balance in Seabirds. Biol Mar Birds. 2001; doi:

$770 \quad 10.1201 / 9781420036305-17$.

771 57. C. Silva M, Chibucos M, Munro JB, Daugherty S, Coelho MM, C. Silva J. Signature of

772 adaptive evolution in olfactory receptor genes in Cory's Shearwater supports molecular

773 basis for smell in procellariiform seabirds. Sci Reports 2020 101. 2020; doi:

774 10.1038/s41598-019-56950-6.

775 58. Gagliardo A, Bried J, Lambardi P, Luschi P, Wikelski M, Bonadonna F. Oceanic

776 navigation in Cory's shearwaters: Evidence for a crucial role of olfactory cues for homing

777 after displacement. J Exp Biol. 2013; doi: 10.1242/JEB.085738.

778 59. Pollonara E, Luschi P, Guilford T, Wikelski M, Bonadonna F, Gagliardo A. Olfaction

779 and topography, but not magnetic cues, control navigation in a pelagic seabird:

780 displacements with shearwaters in the Mediterranean Sea. Sci Reports 2015 51. 2015;

781 doi: 10.1038/srep16486. 
782

783

784

785

786

787

788

789

790

791

792

793

794

795

796

797

798

799

800

801

802

803

804

805

806

807

60. Padget O, Dell'Ariccia G, Gagliardo A, González-Solís J, Guilford T. Anosmia impairs homing orientation but not foraging behaviour in free-ranging shearwaters. Sci Reports 2017 71. 2017; doi: 10.1038/s41598-017-09738-5.

61. Bonadonna F, Nevitt GA. Partner-specific odor recognition in an Antarctic seabird.

Science. 2004; doi: 10.1126/SCIENCE.1103001.

62. Strandh M, Westerdahl H, Pontarp M, Canbäck B, Dubois MP, Miquel C, et al.. Major histocompatibility complex class II compatibility, but not class I, predicts mate choice in a bird with highly developed olfaction. Proc R Soc B Biol Sci. 2012; doi:

10.1098/RSPB.2012.1562.

63. Hoover B, Alcaide M, Jennings S, Sin SYW, Edwards S V., Nevitt GA. Ecology can inform genetics: Disassortative mating contributes to MHC polymorphism in Leach's stormpetrels (Oceanodroma leucorhoa). Mol Ecol. 2018; doi: 10.1111/MEC.14801.

64. Bonadonna F, Bretagnolle V. Smelling home: a good solution for burrow-finding in nocturnal petrels? J Exp Biol. 2002; doi: 10.1242/JEB.205.16.2519.

65. Nevitt GA, Veit RR, Kareiva P. Dimethyl sulphide as a foraging cue for Antarctic Procellariiform seabirds. Nat 1995 3766542. 1995; doi: 10.1038/376680ao.

66. Nevitt GA. Sensory ecology on the high seas: the odor world of the procellariiform seabirds. J Exp Biol. 2008; doi: 10.1242/JEB.015412.

67. Yung S, Sin W, Cloutier A, Nevitt G, Edwards S V. Olfactory receptor subgenome and expression in a highly olfactory procellariiform seabird. bioRxiv. 2019; doi:

$10.1101 / 723924$.

68. Bastos R, Martins B, Cabral JA, Ceia FR, Ramos JA, Paiva VH, et al.. Oceans of stimuli: an individual-based model to assess the role of olfactory cues and local enhancement in seabirds' foraging behaviour. Anim Cogn 2020 234. 2020; doi: 10.1007/S10071-020-01368-1.

69. Khan JS, Provencher JF, Forbes MR, Mallory ML, Lebarbenchon C, McCoy KD. 
808 Parasites of seabirds: A survey of effects and ecological implications. Adv Mar Biol. 2019;

809 doi: 10.1016/BS.AMB.2019.02.001.

810 70. McCoy KD, Dietrich M, Jaeger A, Wilkinson DA, Bastien M, Lagadec E, et al.. The role

811 of seabirds of the lles Eparses as reservoirs and disseminators of parasites and

812 pathogens. Acta Oecologica (Montrouge, Fr. 2016; doi: 10.1016/J.ACTAO.2015.12.013.

813 71. Bensaoud C, Nishiyama MY, Ben Hamda C, Lichtenstein F, Castro De Oliveira U,

814 Faria F, et al.. De novo assembly and annotation of Hyalomma dromedarii tick (Acari:

815 Ixodidae) sialotranscriptome with regard to gender differences in gene expression.

816 Parasites Vectors 2018 111. 2018; doi: 10.1186/S13071-018-2874-9.

817 72. Cobb S. The Size of the Olfactory Bulb in 108 Species of Birds. Auk. 1968; doi:

$818 \quad 10.2307 / 4083624$.

819 73. Zimin A V., Puiu D, Luo MC, Zhu T, Koren S, Marçais G, et al.. Hybrid assembly of the

820 large and highly repetitive genome of Aegilops tauschii, a progenitor of bread wheat, with

821 the MaSuRCA mega-reads algorithm. Genome Res. 2017; doi: 10.1101/gr.213405.116.

822 74. De Coster W, D’Hert S, Schultz DT, Cruts M, Van Broeckhoven C. NanoPack:

823 visualizing and processing long-read sequencing data. Berger B, editor. Bioinformatics.

824 2018; doi: 10.1093/bioinformatics/bty149.

825 75. Marçais G, Yorke JA, Zimin A. QuorUM: An error corrector for Illumina reads. PLoS

826 One. 2015; doi: 10.1371/journal.pone.0130821.

827 76. Laetsch DR, Blaxter ML. BlobTools: Interrogation of genome assemblies.

828 F1000Research. 2017; doi: 10.12688/f1000research.12232.1.

829 77. Seppey M, Manni M, Zdobnov EM. BUSCO: Assessing genome assembly and

830 annotation completeness. Methods Mol Biol.

831 78. Kriventseva E V., Kuznetsov D, Tegenfeldt F, Manni M, Dias R, Simão FA, et al..

832 OrthoDB v10: Sampling the diversity of animal, plant, fungal, protist, bacterial and viral 833 genomes for evolutionary and functional annotations of orthologs. Nucleic Acids Res. 
834

\section{5}

836

837

838

2019; doi: 10.1093/nar/gky1053.

79. Dobin A, Davis CA, Schlesinger F, Drenkow J, Zaleski C, Jha S, et al.. STAR: Ultrafast universal RNA-seq aligner. Bioinformatics. 2013; doi: 10.1093/bioinformatics/bts635.

80. Grabherr MG, Haas BJ, Yassour M, Levin JZ, Thompson DA, Amit I, et al.. Full-length transcriptome assembly from RNA-Seq data without a reference genome. Nat Biotechnol. 2011; doi: 10.1038/nbt. 1883 .

81. Fu L, Niu B, Zhu Z, Wu S, Li W. CD-HIT: accelerated for clustering the next-generation sequencing data. Bioinformatics. 2012; doi: 10.1093/bioinformatics/bts565.

82. Li W, Godzik A. Cd-hit: a fast program for clustering and comparing large sets of protein or nucleotide sequences. Bioinformatics. 2006; doi: 10.1093/bioinformatics/btl158. 83. Dierckxsens N, Mardulyn P, Smits G. NOVOPlasty: De novo assembly of organelle genomes from whole genome data. Nucleic Acids Res. 2017; doi: 10.1093/nar/gkw955.

84. Bernt M, Donath A, Jühling F, Externbrink F, Florentz C, Fritzsch G, et al.. MITOS: Improved de novo metazoan mitochondrial genome annotation. Mol Phylogenet Evol. 2013; doi: 10.1016/j.ympev.2012.08.023.

85. Smit AF., Hubley R, Green P. RepeatMasker.

86. Storer J, Hubley R, Rosen J, Wheeler TJ, Smit AF. The Dfam community resource of transposable element families, sequence models, and genome annotations. Mob DNA. 2021; doi: 10.1186/s13100-020-00230-y.

87. Jurka J, Kapitonov V V., Pavlicek A, Klonowski P, Kohany O, Walichiewicz J. Repbase Update, a database of eukaryotic repetitive elements. Cytogenet Genome Res. 2005; doi: 10.1159/000084979.

88. Jones P, Binns D, Chang HY, Fraser M, Li W, McAnulla C, et al.. InterProScan 5: Genome-scale protein function classification. Bioinformatics. 2014; doi: 10.1093/bioinformatics/btu031.

89. Camacho C, Coulouris G, Avagyan V, Ma N, Papadopoulos J, Bealer K, et al.. 
860 BLAST+: Architecture and applications. BMC Bioinformatics. 2009; doi: 10.1186/1471-

$861 \quad 2105-10-421$.

862 90. Altschul SF, Gish W, Miller W, Myers EW, Lipman DJ. Basic local alignment search

863 tool. J Mol Biol. 1990; doi: 10.1016/S0022-2836(05)80360-2.

864 91. Boutet E, Lieberherr D, Tognolli M, Schneider M, Bansal P, Bridge AJ, et al..

865 Uniprotkb/swiss-prot, the manually annotated section of the uniprot knowledgebase: How

866 to use the entry view. Methods Mol Biol.

867 92. Nawrocki EP, Kolbe DL, Eddy SR. Infernal 1.0: Inference of RNA alignments.

868 Bioinformatics. 2009; doi: 10.1093/bioinformatics/btp157.

869 93. Chan PP, Lowe TM. tRNAscan-SE: Searching for tRNA genes in genomic sequences.

870 Methods Mol Biol.

871 94. Li H, Durbin R. Fast and accurate short read alignment with Burrows-Wheeler

872 transform. Bioinformatics. 2009; doi: 10.1093/bioinformatics/btp324.

873 95. Gower G, Tuke S, Rohrlach AB, Soubrier J, Llamas B, Bean N, et al.. Population size

874 history from short genomic scaffolds: how short is too short? bioRxiv. 2018; doi:

$87510.1101 / 382036$.

876 96. Yamashina Y, Udagawa T. The chromosomes of the streaked shearwater Puffinus

877 leucomelas (Vieillot). J Yamashina Inst Ornithol. 1:220-11954;

878 97. Robinson JA, Räikkönen J, Vucetich LM, Vucetich JA, Peterson RO, Lohmueller KE, et

879 al.. Genomic signatures of extensive inbreeding in Isle Royale wolves, a population on the

880 threshold of extinction. Sci Adv. 2019; doi:

881 10.1126/SCIADV.AAU0757/SUPPL_FILE/AAU0757_SM.PDF.

882 98. Li H. Aligning sequence reads, clone sequences and assembly contigs with BWA-

883 MEM. 2013;

884 99. McKenna A, Hanna M, Banks E, Sivachenko A, Cibulskis K, Kernytsky A, et al.. The 885 genome analysis toolkit: A MapReduce framework for analyzing next-generation DNA 
886 sequencing data. Genome Res. 2010; doi: 10.1101/gr.107524.110.

887 100. Danecek P, Auton A, Abecasis G, Albers CA, Banks E, DePristo MA, et al.. The

888 variant call format and VCFtools. Bioinformatics. 2011; doi: 10.1093/bioinformatics/btr330.

889 101. Emms DM, Kelly S. OrthoFinder: Phylogenetic orthology inference for comparative

890 genomics. Genome Biol. 2019; doi: 10.1186/s13059-019-1832-y.

891 102. Löytynoja A. Phylogeny-aware alignment with PRANK. Methods Mol Biol. 2014; doi:

892 10.1007/978-1-62703-646-7_10.

893 103. Kumar S, Stecher G, Li M, Knyaz C, Tamura K. MEGA X: Molecular evolutionary

894 genetics analysis across computing platforms. Mol Biol Evol. 2018; doi:

$89510.1093 / \mathrm{molbev} / \mathrm{msy096}$.

896 104. Nguyen LT, Schmidt HA, Von Haeseler A, Minh BQ. IQ-TREE: A fast and effective

897 stochastic algorithm for estimating maximum-likelihood phylogenies. Mol Biol Evol. 2015;

898 doi: 10.1093/molbev/msu300.

899 105. Kalyaanamoorthy S, Minh BQ, Wong TKF, Von Haeseler A, Jermiin LS. ModelFinder:

900 Fast model selection for accurate phylogenetic estimates. Nat Methods. 2017; doi:

$901 \quad 10.1038 /$ nmeth.4285.

902 106. Hoang DT, Chernomor O, Von Haeseler A, Minh BQ, Vinh LS. UFBoot2: Improving

903 the ultrafast bootstrap approximation. Mol Biol Evol. 2018; doi: 10.1093/molbev/msx281.

904 107. Zhang C, Rabiee M, Sayyari E, Mirarab S. ASTRAL-III: Polynomial time species tree

905 reconstruction from partially resolved gene trees. BMC Bioinformatics. 2018; doi:

906 10.1186/s12859-018-2129-y.

907 108. Sanderson MJ. r8s: Inferring absolute rates of molecular evolution and divergence

908 times in the absence of a molecular clock. Bioinformatics. 2003; doi:

909 10.1093/bioinformatics/19.2.301.

910 109. Braun EL, Kimball RT, Han KL, luhasz-Velez NR, Bonilla AJ, Chojnowski JL, et al..

911 Homoplastic microinversions and the avian tree of life. BMC Evol Biol. 2011; doi: 
912

913

914

915

916

917

918

919

920

921

922

923

924

925

926

927

928

929

930

931

932

933

934

935

936

937

10.1186/1471-2148-11-141.

110. Subramanian S, Beans-Picón G, Swaminathan SK, Millar CD, Lambert DM. Evidence

for a recent origin of penguins. Biol Lett. 2013; doi: 10.1098/RSBL.2013.0748.

111. Claramunt S, Cracraft J. Evolutionary Ecology: A new time tree reveals Earth

history's imprint on the evolution of modern birds. Sci Adv. 2015; doi:

10.1126/SCIADV.1501005/SUPPL_FILE/1501005_SM.PDF.

112. Prum RO, Berv JS, Dornburg A, Field DJ, Townsend JP, Lemmon EM, et al.. A

comprehensive phylogeny of birds (Aves) using targeted next-generation DNA

sequencing. Nat 2015 5267574. 2015; doi: 10.1038/nature15697.

113. Kumar S, Stecher G, Suleski M, Hedges SB. TimeTree: A Resource for Timelines,

Timetrees, and Divergence Times. Mol Biol Evol. 2017; doi: 10.1093/molbev/msx116.

114. Kosakovsky Pond SL, Frost SDW, Muse S V.. HyPhy: Hypothesis testing using

phylogenies. Bioinformatics. 2005; doi: 10.1093/bioinformatics/bti079.

115. Wu M, Chatterji S, Eisen JA. Accounting for alignment uncertainty in phylogenomics.

PLoS One. 2012; doi: 10.1371/journal.pone.0030288.

116. Smith MD, Wertheim JO, Weaver S, Murrell B, Scheffler K, Kosakovsky Pond SL.

Less is more: An adaptive branch-site random effects model for efficient detection of

episodic diversifying selection. Mol Biol Evol. 2015; doi: 10.1093/molbev/msv022.

117. Wertheim JO, Murrell B, Smith MD, Pond SLK, Scheffler K. RELAX: Detecting

relaxed selection in a phylogenetic framework. Mol Biol Evol. 2015; doi:

10.1093/molbev/msu400.

118. Falcon S, Gentleman R. Using GOstats to test gene lists for GO term association.

Bioinformatics. 2007; doi: 10.1093/bioinformatics/btl567.

119. Librado P, Vieira FG, Rozas J. BadiRate: Estimating family turnover rates by

likelihood-based methods. Bioinformatics. 2012; doi: 10.1093/bioinformatics/btr623.

120. Challis R, Richards E, Rajan J, Cochrane G, Blaxter M. BlobToolKit - Interactive 
938 Quality Assessment of Genome Assemblies. G3 Genes/Genomes/Genetics. 2020; doi:

$93910.1534 / G 3.119 .400908$.

940 121. Augustin L, Barbante C, Barnes PRF, Barnola JM, Bigler M, Castellano E, et al..

941 Eight glacial cycles from an Antarctic ice core. Nat 2004 4296992. 2004; doi:

$942 \quad 10.1038 /$ nature02599.

943 122. Lisiecki LE, Raymo ME. A Pliocene-Pleistocene stack of 57 globally distributed

944 benthic $\delta 180$ records. Paleoceanography. 2005; doi: 10.1029/2004PA001071.

945

946

947

948

949

950

951

952

953

954

955

956

957

\section{4}

Table 1. Sequencing data, library information and samples used in this study

\begin{tabular}{|l|l|l|l|l|l|}
\hline Library & $\begin{array}{l}\text { Total number of } \\
\text { base pairs }\end{array}$ & $\begin{array}{l}\text { Number of } \\
\text { reads }\end{array}$ & $\begin{array}{l}\text { Coverag } \\
\text { e }\end{array}$ & $\begin{array}{l}\text { Individual } \\
\text { code }\end{array}$ & Location \\
\hline $\begin{array}{l}\text { HiSeq X Ten - } \\
\text { TruSeq DNA PCR } \\
\text { Free. 2x150 bp }\end{array}$ & $143,765,593,200$ & $958,437,288$ & $118 x$ & Male-MII & $\begin{array}{l}\text { Sa Cella } \\
\text { (Mallorca) }\end{array}$ \\
\hline $\begin{array}{l}\text { ONT - Ligation kit } \\
\text { SQK-LSK109 1D }\end{array}$ & $12,142,789,693$ & $2,576,486$ & $10 x$ & $\begin{array}{l}\text { Unsexed- } \\
\text { Ei }\end{array}$ & $\begin{array}{l}\text { Sa } \\
\text { Conillera } \\
\text { (Eivissa) }\end{array}$ \\
\hline $\begin{array}{l}\text { NovaSeq 6000 - } \\
\text { TruSeq RNA } \\
\text { Sample Prep Kit } \\
\text { v2. 2x100 bp }\end{array}$ & $14,997,592,000$ & $149,975,920$ & -- & Chick-Mll & $\begin{array}{l}\text { Conills } \\
\text { islet } \\
\text { (Mallorca) }\end{array}$ \\
\hline
\end{tabular}

\section{Tables}


Table 2. Balearic shearwater genome assembly metrics

959

960

961

962

963

964

965

966

967

968

969

970

971

972

973

974

975

\begin{tabular}{|l|l|}
\hline Assembly length (bp) & $1,218,519,395$ \\
\hline Number of scaffolds & 4,169 \\
\hline Longest scaffold (Mbp) & 11.06 \\
\hline N50 (Mbp) & 2.13 \\
\hline L50 & 164 \\
\hline GC content (\%) & 42.52 \\
\hline Repetitive content (\%) & 9.95 \\
\hline Mitogenome (bp) & 19,855 \\
\hline & \\
\hline No. protein-coding genes & 21,959 \\
\hline & \\
\hline BUSCO \% & \\
\hline Complete & 95.9 \\
\hline \multicolumn{1}{|c|}{ Single copy } & 95.6 \\
\hline \multicolumn{1}{|c|}{ Duplicated } & 0.3 \\
\hline Fragmented & 1.1 \\
\hline Missing & 3.0 \\
\hline
\end{tabular}

\section{Figure legends}

Figure 1. (a) Map depicting the known Balearic shearwater breeding colonies in the Balearic Islands. Circle size is proportional to population size as shown in the legend. Modified from [20] (b) Snail plot summarizing genome assembly statistics [120]. From inside to outside, the light-grey spiral shows the cumulative scaffold count on a log scale with white scale lines depicting changes of order of magnitude. Dark-grey segments show the distribution of scaffold lengths, and the plot radius is scaled to the longest scaffold (shown in red). Orange and light-orange rings represent the N50 and N90 scaffold lengths, respectively. Blue and light-blue rings show GC, AT and N percentages along the genome assembly. (c) MSMC2 reconstruction of effective population size estimates $\left(N_{\mathrm{e}}\right)$ over time, estimated using generation time of 12.8 years and mutation rate of $2.89 \times 10^{-9}$ substitutions per nucleotide per generation. Light-brown vertical bars represent interglacial periods. Upper panel represents global temperature changes as inferred from the EPICA 
976 (European Project for Ice Coring in Antarctica) Dome C ice core [121]. Lower panel

977 represents sea level changes inferred from a stack of 57 globally distributed benthic $\delta 180$

978 records [122].

979

980

981 Figure 2. Comparison of genome-wide heterozygosity among Procellariiformes. (a) 982 Density plots showing the distribution of individual nucleotide diversity $(\pi)$ values in 983 nonoverlapping $25 \mathrm{~Kb}$ windows for each of the eight Procellariiformes species with an 984 available reference genome. Scientific names of large-bodied and small-bodied species 985 are shown in green and orange, respectively. Color-scale represents $\pi$ values tail 986 probabilities as shown in the legend. The white line depicts median values and black lines 987 depict 25th and 75th percentiles. (b) Density plots showing the distribution of $\pi$ values in 988 large-bodied and small-bodied species groups.

989 Figure 3. Ultrametric tree based on the 4D CDS ML tree calibrated with r8s. Minimum 990 number of gains (green) and losses (red) per branch are represented according to 991 BadiRate analysis. Numbers in ancestral nodes and in the tips (in parenthesis) indicate the 992 inferred number of genes. Illustrations of seabird species were reproduced with permission 993 from Lynx Edicions and Martí Franch. 

tail probability

Thalassarche chlororhynchos

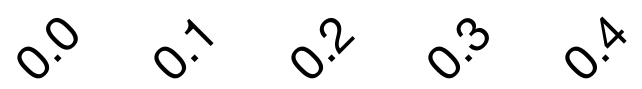

$\mathscr{\infty}$
$\frac{\mathscr{D}}{0}$
$\frac{\mathbb{Q}}{0}$

Fregetta grallaria

Oceanites oceanicus

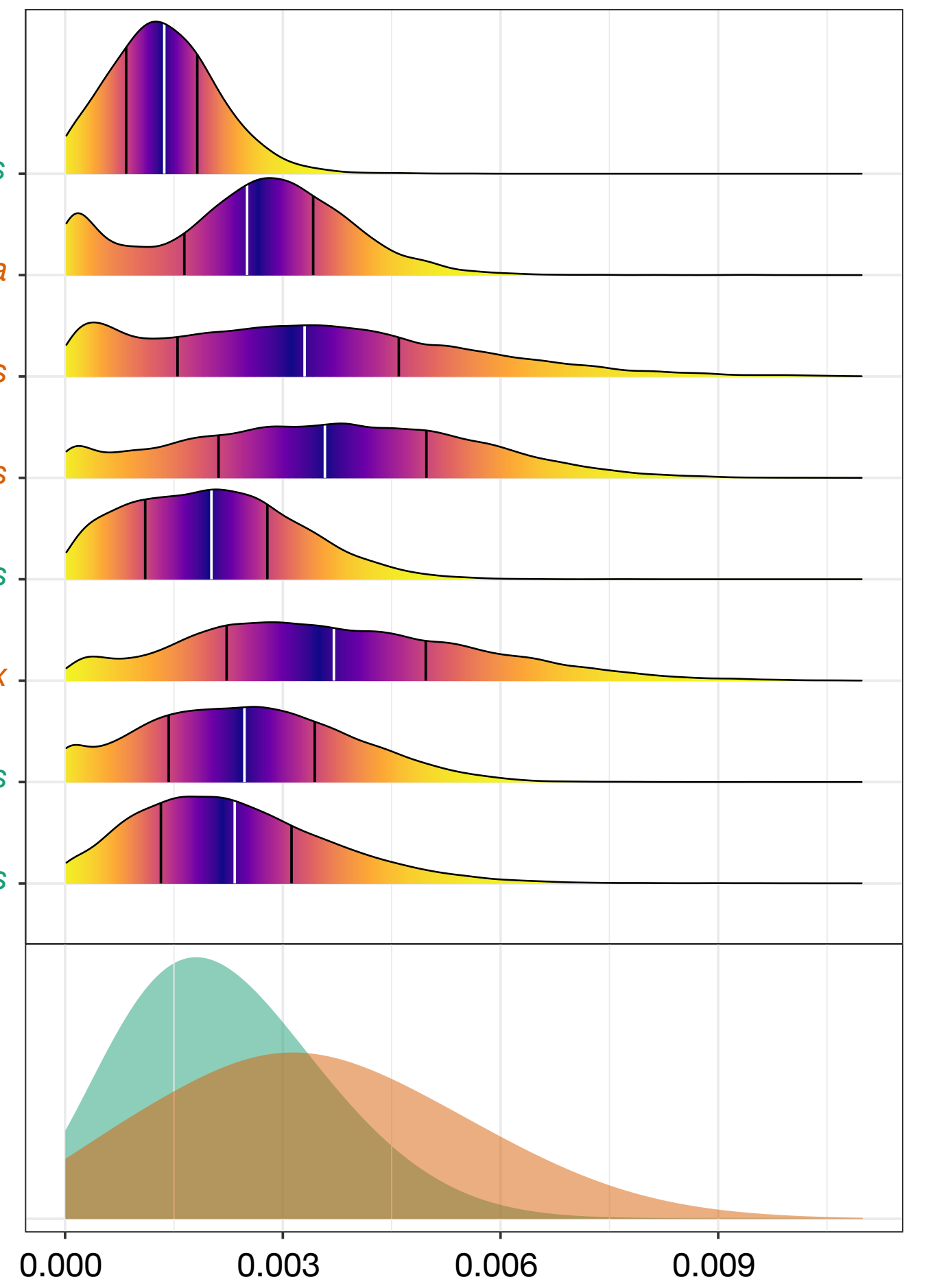

Observed $\pi$

(b)

large-bodied small-bodied

Pelecanoides urinatrix

Puffinus mauretanicus

Hydrobates tethys

Fulmarus glacialis

Calonectris borealis

0.003

0.006 


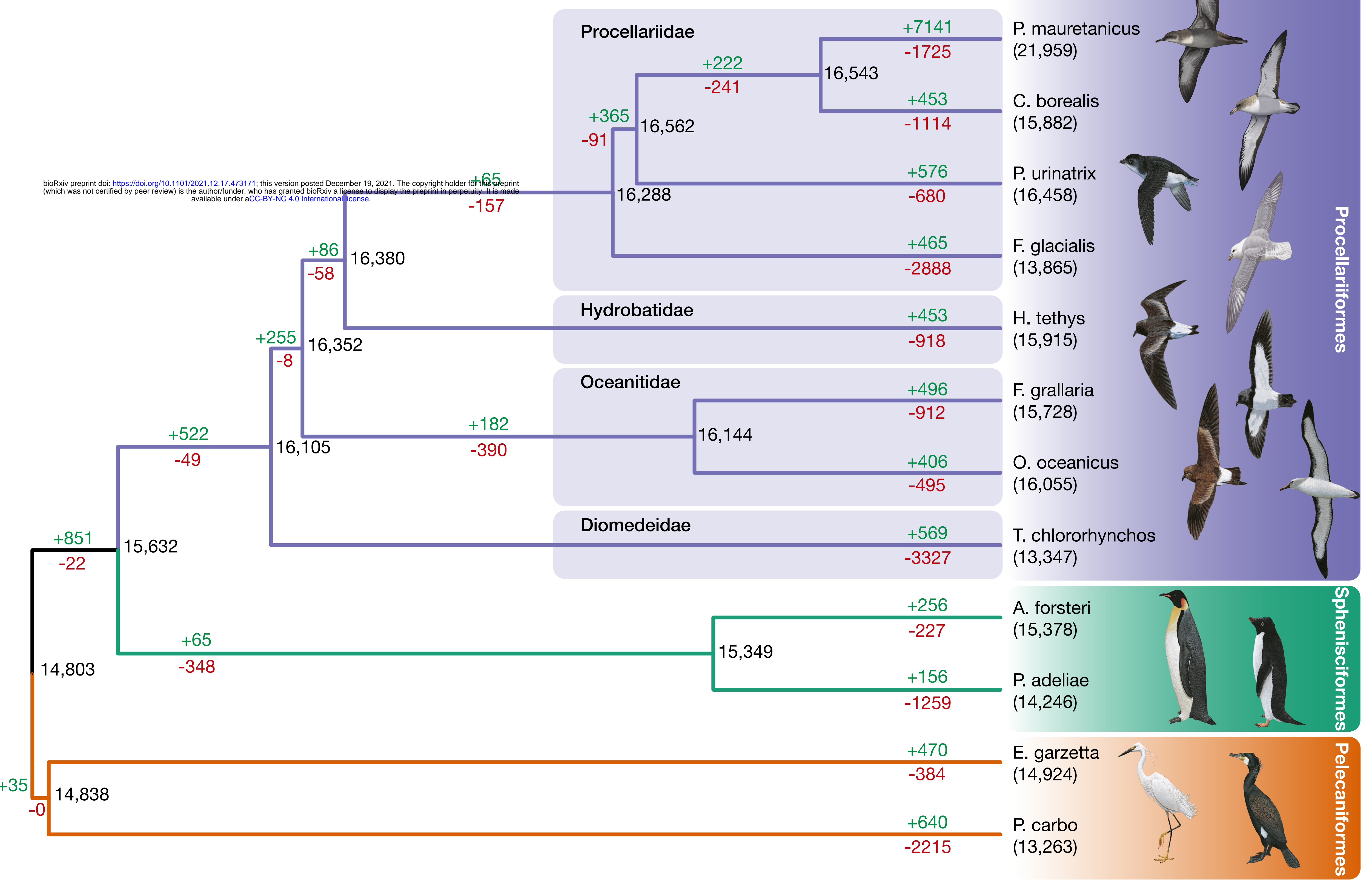

